\title{
PERSEPSI MAHASISWA/I TERHADAP WACANA AMANDEMEN UUD NRI 1945 (Survei terhadap Mahasiswa STEI ITB Angkatan 2018)
}

\author{
Hendra Chayadi S., M. Alamsyah, M. Izzrul Izzrufi, Selma Racinta L, \& Epin Saepudin \\ Institut Teknologi Bandung \\ hendrasuperb03@gmail.com
}

\begin{abstract}
Abstrak
Penelitian ini bertujuan untuk mengetahui persepsi mahasiswa/i Sekolah Teknik Elektro dan Informatika Institut Teknologi Bandung (STEI ITB) angkatan 2018 terhadap wacana amandemen UUD NRI 1945 dengan menggunakan metode pengumpulan data kuantitatif berupa kuesioner yang diberikan kepada 43 responden. Hasil analisis menunjukkan bahwa mayoritas mahasiswa/i STEI ITB 2018 sering mengikuti berita politik yang terjadi di Indonesia melalui media sosial. Mereka juga tidak setuju amandemen UUD NRI 1945 Kelima dilakukan serta dari berbagai responden, mereka berharap, bila amandemen dilakukan, untuk mengoptimalkan alur kerja lembaga pemerintahan tanpa merubah sistem pemerintahan di Indonesia.
\end{abstract}

Kata kunci: Persepsi, Amandemen ke-5, UUD 1945

\section{Abstract}

This study aims to determine the perceptions of students of the School of Electrical and Informatics Engineering, Bandung Institute of Technology (STEI ITB) class of 2018 on the discourse on the amendments to the 1945 Constitution of the Republic of Indonesia by using quantitative data collection methods in the form of questionnaires given to 43 respondents. The results of the analysis show that the majority of STEI ITB 2018 students often follow political news that occurs in Indonesia through social media. They also disagreed that the amendment of the Fifth NRI 1945 Constitution was carried out and from various respondents, they hoped, if the amendment was carried out, to optimize the workflow of government institutions without changing the government system in Indonesia.

Keywords: Perception, 5th amendment, UUD 1945

\section{PENDAHULUAN}

Saat ini, banyak berita yang terjadi di Indonesia. Berita yang beredar melingkupi bidang ekonomi, politik, sosial, dan banyak bidang lainnya. Berita tersebut ditujukan untuk menyadarkan berbagai kalangan masyarakat tentang situasi terkini yang terjadi di Indonesia. Salah satu berita yang marak dikabarkan di Indonesia akhir-akhir ini adalah wacana amandemen Undang Undang Dasar (UUD) 1945 yang ke-5 (Dewantara, Hermawan, et al., 2021).

UUD berperan sebagai sebuah konstitusi di Indonesia. Konstitusi adalah kerangka masyarakat politik, yang diorganisir berdasarkan hukum, yang membentuk lembaga-lembaga permanen dengan tugas dan wewenang tertentu (Dewantara, Nurgiansah, et al., 2021). Dengan demikian, konstitusi adalah kumpulan prinsip-prinsip yang mengatur kekuasaan pemerintah, hak-hak rakyat dan hubungan antara kedua hal tersebut. (Dahlan Thaib, 2007).

Lord Bryce berpendapat bahwa sebuah negara memiliki Undang - Undang karena beberapa alasan: adanya kehendak para warga dari negara yang bersangkutan agar terjamin hak-haknya dan bertujuan untuk membatasi tindakan-tindakan para penguasa di negara tersebut, adanya kehendak dari para penguasa negara dan atau rakyatnya untuk menjamin agar terdapat pola atau sistem tertentu atas pemerintahan negaranya, adanya kehendak para pembentuk negara tersebut agar terdapat kepastian tentang cara penyelenggaraan ketatanegaraannya, dan adanya kehendak dari beberapa negara yang semula masing-masing berdiri 
sendiri, untuk menjalin kerjasama (Dewantara \& Nurgiansah, 2021b).

Berdasarkan pendapat di atas, UUD dibentuk atas keterlibatan beberapa elemen: warga negara, pembentuk negara, serta negara lain. Di Indonesia, para pembentuk negara (founding fathers) membentuk sebuah Undang-Undang Dasar untuk membentuk kepastian hukum dalam satu negara (Nurgiansah et al., 2020). Hal tersebut membentuk UUD 1945 yang kita anut hingga saat ini. UUD 1945 dibentuk pada 18 Agustus 1945 satu hari setelah pernyataan kemerdekaan oleh PPKI. Selama beberapa tahun, UUD 1945 berganti sesuai kondisi negara pada saat itu, dimulai dari Konstitusi RIS (1949), UUD Sementara (1950), dan konstitusi diganti kembali ke UUD 1945 atas keputusan Presiden pada Dekrit Presiden 5 Juli 1959. Konstitusi inilah yang mengalami perubahan hingga saat ini (amandemen).

Amandemen secara tata bahasa berasal dari bahasa Inggris yaitu "amend" yang artinya "rubah". Amendemen dalam pengertian hukum ketatanegaraan dapat diartikan sebagai: mengubah, atau menambah atau bahkan menghapus ketentuan di dalam ketentuan hukum dan perundang - undangan.

Amandemen UUD 1945 sudah terjadi sebanyak 4 kali, amandemen pertama terjadi pada tanggal 14-21 Oktober 1999, amandemen kedua terjadi pada tanggal 718 Agustus 2001, amandemen ketiga terjadi pada tanggal 1-9 September 2001, dan amandemen keempat terjadi pada tanggal 1-9 Agustus 2002.

Banyak pokok pikiran baru yang diadopsikan ke dalam kerangka UUD 1945: perihal cita demokrasi dan nomokrasi, pemisahan kekuasaan dan prinsip checks and balances, sistem pemerintahan presidensial, format kelembagaan baru, dan banyak hal penting lainnya. (Jimly Asshiddiqie, 2007).

Berdasarkan UU No. 25 Tahun 2004,
Amandemen UUD 1945 juga menyebabkan perubahan dalam pengelolaan pembangunan: penguatan kedudukan lembaga legislatif dalam penyusunan Anggaran Pendapatan dan Belanja Negara (APBN), ditiadakannya Garis-Garis Besar Haluan Negara (GBHN) sebagai pedoman penyusunanrencana pembangunan nasional, dan diperkuatnya otonomi daerah dan desentralisasi pemerintahan dalam Negara Kesatuan Republik Indonesia. (Yesi Anggraini dkk., 2015).

Amandemen UUD 1945 disesuaikan dengan pengaruh berbagai perkembangan yang bergerak dinamis, dimulai dari zaman kemerdekaan hingga zaman Reformasi (Nurgiansah, 2021a). Melihat pengaruh perkembangan negara di zaman sekarang, terdapat sebuah wacana untuk melakukan amandemen kelima UUD 1945. Hal tersebut dilakukan untuk memperbaiki kelemahan dalam UUD 1945. Namun, terdapat kontroversi menyangkut hal ini. Beberapa orang setuju terhadap topik ini karena amandemen dapat memperbaiki cacat substansi, proses, dan format lembaga pemerintahan di Indonesia, dan beberapa orang tidak setuju karena amandemen dapat memicu kembalinya GBHN dan mengubah sistem pemerintahan di Indonesia menjadi sistem parlementer(Dewantara \& Nurgiansah, 2021a).

Melihat urgensi masalah ini, rakyat Indonesia perlu tahu tentang hal tersebut. Mahasiswa termasuk salah satunya. Bila ada suara rakyat yang perlu digaungkan, mahasiswa menjadi garda terdepan dalam menyuarakan aspirasi rakyat. Terdapat beberapa sarana rakyat untuk mengetahui kondisi politik Indonesia: majalah berita, media sosial, televisi, dll. Namun, beberapa berita yang tersebar dapat mengandung misinformasi yang berujung kepada miskomunikasi rakyat. Berita kadang digunakan oleh pihak atau oknum tertentu untuk mendorong ide atau tujuan mereka. 
Ada pula berita yang tersebar dari sumber berita lain yang menyebabkan penyimpangan informasi berita dari fakta sebenarnya. Berita-berita ini sering kali tersebar melalui mulut ke mulut (personal). Dengan perkembangan teknologi informasi sekarang, berita-berita ini semakin cepat tersebar. Berita ini dapat menyebabkan efek yang buruk seperti miskomunikasi yang menyebabkan perpecahan diantara masyarakat atau bahkan kepanikan massal. Oleh karena itu, diperlukannya pemikiran kritis dan persepsi sendiri dalam memahami berita yang tersebar.

Pada masa perkembangan teknologi komunikasi, internet merupakan keperluan dasar banyak orang, termasuk mahasiswa. Mahasiswa menggunakan Internet dalam mencari informasi dan berkomunikasi serta menempuh pendidikannya (Nurgiansah, 2021b). Mahasiswa juga menggunakan media sosial sebagai sarana berinteraksi ke teman maupun dosen (Nurgiansah \& Pringgowijoyo, 2020). Media sosial merupakan salah satu alat bagi mahasiswa untuk mencari informasi, berita termasuk salah satunya. Ada setidaknya $98 \%$ mahasiswa mengaku sebagai pengguna aktif internet dan 95\% diantaranya merupakan pengguna aktif media sosial. Media sosial yang sering digunakan mahasiswa secara menurun berdasarkan banyaknya pengguna yaitu Whatsapp (96\%), Instagram (90\%), Youtube (74\%), Line (58\%), dan Facebook (36\%). Sedangkan tujuan utama mereka dalam menggunakan media sosial secara menurun yaitu alat komunikasi (87\%), mencari informasi (82\%), interaksi sosial (57\%), hiburan (56\%), dan menyampaikan opini (22\%) (Andi Saputra, 2019).

Melihat mahasiswa merupakan salah satu elemen penerus bangsa, mereka perlu mawas akan kondisi di Indonesia saat ini. Salah satu caranya adalah dengan mengikuti berita politik di Indonesia.
Pemikiran kritis serta persepsi mahasiswa/i dapat bermanfaat untuk mengembangkan Indonesia menjadi lebih baik dengan cara berkontribusi di bidangnya masing - masing. Mereka juga mempunyai hak istimewa dalam menyuarakan aspirasi kepada lembaga pemerintah, dan rakyat pun ikut membantu mereka dengan caranya masing - masing agar aspirasi dapat tersampaikan dan terdengar ke wakil-wakil rakyat (Nurgiansah \& Widyastuti, 2020).

Melihat hal tersebut, kami ingin mengetahui persepsi mahasiswa/i terhadap wacana amandemen UUD 1945 ke-5. Penelitian ini dilakukan dengan target lingkungan terdekat, yaitu mahasiswa/i ITB Sekolah Teknik Elektro dan Informatika (STEI) angkatan 2018,

\section{METODE PENELITIAN}

Metode penelitian yang digunakan adalah penelitian kuantitatif berupa survei terhadap mahasiswa/i ITB dari Sekolah Teknik Elektro Indonesia (STEI) angkatan 2018. Penelitian ini dilakukan dengan menyebarkan sebuah formulir daring melalui google form ke grup atau personal mahasiswa/i. Tahap awal penelitian yaitu pemilihan subjek, di kasus ini mahasiswa/i yang dekat dengan peneliti. Kemudian melakukan kontak melalui sosial media berupa Line dan WA untuk menyebarkan formulir. Proses ini akan menghasilkan data kuantitatif berupa grafik dan kualitatif berupa pandangan atau tanggapan mahasiswa/i. Data ini kemudian dianalisis untuk menentukan Persepsi dan persepsi mahasiswa/i terhadap wacana amandemen UUD 1945.

Pengisian formulir berisi data identitas mahasiswa/i berupa nama, NIM, serta fakultas. Hal ini dilakukan untuk validasi data yang masuk. Kemudian, mereka diarahkan ke bagian pertanyaan mengenai keseringan mereka menonton atau membaca berita politik Indonesia dan 
P-ISSN: 1978-0184 E-ISSN: 2723-2328

media yang digunakan dalam memperoleh berita tersebut. Proses berikutnya berupa pertanyaan mengenai Persepsi, isi, dan dampak amandemen UUD 1945. Bagian ini akan menghasilkan data berupa pandangan mahasiswa/i terhadap isu ini. Bagian terakhir dari formulir ini adalah pemaparan berita yang telah kami rangkum dan pengumpulan pandangan mereka berdasarkan informasi tersebut. Hasil akhir dari formulir ini berupa konfirmasi keinginan mahasiswa/i terhadap amandemen UUD 1945 dan harapan mereka bila amandemen itu terjadi.

\section{HASIL PENELITIAN DAN PEMBAHASAN Hasil Penelitian}

Hasil penelitian menunjukkan terdapat 46 responden mahasiswa/i ITB STEI '18 dalam kuesioner yang telah dibagikan. Berikut data frekuensi mahasiswa/I dalam mengikuti berita-berita politik di Indonesia.

Tabel 1. Frekuensi Mahasiswa dalam

Mengikuti Berita Politik di Indonesia

\begin{tabular}{|c|c|c|}
\hline No. & Frekuensi & Jumlah Mahasiswa \\
\hline 1 & Jarang $<1$ & $11(23,9 \%)$ \\
\hline 2 & Kadang $<2$ & $18(39,1 \%)$ \\
\hline 3 & Sering <3 & $11(23,9 \%)$ \\
\hline 4 & Biasanya $<4$ & $6(13 \%)$ \\
\hline Rata-Rata Frekuensi & Sering (2,261\%) \\
\hline Jumlah mahasiswa yang & Ya : 29 Mahasiswa \\
pernah mendengar isu \\
wacana Amandemen UUD \\
\cline { 2 - 2 } NRI 1945 & Tidak : 17 Mahasiswa \\
\end{tabular}

Berdasarkan tabel 1, rata-rata mahasiswa/i sering mengikuti berita politik di Indonesia. Hal ini dapat dilihat Berdasarkan data pada tabel 2, mahasiswa/i paling banyak mengakses berita pada tiga platform: media sosial dengan persentase sebesar $80.4 \%$, Youtube dengan persentase sebesar $54,3 \%$, serta TV dengan persentase sebesar 37\%.

Tabel 2. Platform yang Digunakan Mahasiswa/i dalam Mengakses Berita

\begin{tabular}{|c|c|c|}
\hline No. & Media & $\begin{array}{c}\text { Jumlah } \\
\text { Mahasiswa }\end{array}$ \\
\hline 1. & TV & $17(37 \%)$ \\
\hline 2. & Youtube & $25(54.3 \%)$ \\
\hline 3. & Media Sosial & $37(80.4 \%)$ \\
\hline 4. & Percakapan Dengan Dosen & $2(4.3 \%)$ \\
\hline 5. & Diskusi Dengan Teman & $12(26.1 \%)$ \\
\hline 6. & Berita Daring & $1(2.2 \%)$ \\
\hline
\end{tabular}

Berdasarkan data pada tabel 2, mahasiswa/i paling banyak mengakses berita pada tiga platform: media sosial dengan persentase sebesar $80.4 \%$, Youtube dengan persentase sebesar

$54,3 \%$, serta TV dengan persentase sebesar $37 \%$.

Berikutnya adalah data sikap dan tanggapan mahasiswa terhadap amandemen UUD NRI 1945.

Tabel 3. Sikap Mahasiswa terhadap Amandemen UUD NRI 1945

\begin{tabular}{|c|c|c|c|}
\hline \multicolumn{4}{|c|}{ Sebelum Mengetahui Konteks Amandemen } \\
\hline $\begin{array}{c}\text { Tidak } \\
\text { Setuju }\end{array}$ & $\begin{array}{c}\text { Kurang } \\
\text { Setuju }\end{array}$ & $\begin{array}{c}\text { Cukup } \\
\text { Setuju }\end{array}$ & Setuju \\
\hline $3(6.5 \%)$ & $24(52.2 \%)$ & $17(37 \%)$ & $2(4.3 \%)$ \\
\hline \multicolumn{2}{|c|}{ Sebelum Mengetahui Konteks Amandemen } \\
\hline \multicolumn{2}{|c|}{ Tidak Perlu } & \multicolumn{2}{c|}{ Perlu } \\
\hline \multicolumn{2}{|c|}{$33(73.3 \%)$} \\
\hline
\end{tabular}

Berdasarkan data tabel 3, mahasiswa cenderung kurang setuju terhadap adanya Amandemen UUD NRI 1945 serta tidak perlunya terjadi Amandemen. Dari sikap tersebut, berikut adalah pendapat mahasiswa/i terhadap dampak yang timbul bila Amandemen UUD NRI 1945 terjadi :

Tabel 4. Tanggapan Mahasiswa terhadap Dampak Amandemen UUD NRI 1945

\begin{tabular}{|c|c|c|}
\hline Dampak & Pandangan & $\begin{array}{c}\text { Jumlah } \\
\text { Mahasiswa }\end{array}$ \\
\hline "Mematikan" & Setuju & $8(17.6 \%)$ \\
\cline { 2 - 3 } demokrasi di Indonesia \\
[rzn/hp, dw.com] & Tidak & $38(82.4 \%)$ \\
\hline Perpanjangan Jabatan & Setuju & \\
Presiden menjadi 3 & Setuju & $10(21.7 \%)$ \\
\cline { 2 - 3 } $\begin{array}{c}\text { Periode [cnn.com dan } \\
\text { republika.co.id] }\end{array}$ & Setuju & $36(78.3 \%)$ \\
\hline $\begin{array}{c}\text { Mengembalikan GBHN } \\
\text { dan Mengubah Sistem } \\
\text { Pemerintahan di }\end{array}$ & Setuju & $11(23.9 \%)$ \\
\cline { 2 - 3 } & Tidak & $35(76.1 \%)$ \\
\hline
\end{tabular}




\begin{tabular}{|c|c|c|}
\hline $\begin{array}{l}\text { Indonesia menjadi } \\
\text { Parlementer [Fajri } \\
\text { Nursyamsi, dkk., } \\
\text { pshk.or.id] }\end{array}$ & & \\
\hline \multirow{2}{*}{$\begin{array}{c}\text { Optimisasi Alur Kerja } \\
\text { Lembaga Pemerintah } \\
\text { [Syamsuddin Haris, } \\
\text { lipi.go.id] }\end{array}$} & Setuju & $37(80.4 \%)$ \\
\hline & $\begin{array}{l}\text { Tidak } \\
\text { Setuju }\end{array}$ & $9(19.6 \%)$ \\
\hline
\end{tabular}

Berdasarkan data tabel 4, terdapat sebanyak $82,4 \%$ berpandangan tidak setuju terhadap dampak 1 "Mematikan" demokrasi di Indonesia [rzn/hp, dw.com]. 78,3\% mahasiswa tidak setuju terhadap dampak 2 Perpanjangan Jabatan Presiden menjadi 3 Periode [cnn.com dan republika.co.id], $\quad 76,1 \%$ mahasiswa berpandangan tidak setuju terhadap dampak 3 Mengembalikan GBHN dan Mengubah Sistem Pemerintahan di Indonesia menjadi Parlementer [Fajri Nursyamsi, dkk., pshk.or.id], serta 80,4\% mahasiswa berpandangan setuju terhadap dampak 4 Optimisasi Alur Kerja Lembaga Pemerintah [Syamsuddin Haris, lipi.go.id].

\section{Pembahasan}

Berdasarkan data tabel 1, ditunjukkan bahwa hanya sebagian mahasiswa yang memiliki kebiasaan dalam mengakses berita, secara sengaja atau tidak. Dengan mayoritas jawabannya berada pada tingkatan kadang. Hasil pengolahan data ini menunjukkan nilai sering dengan indeks 2.261. Namun walaupun nilai berada pada rentang sering, nilai ini lebih memiliki kecondongan menuju ke frekuensi kadang. Hal ini berarti mahasiswa memiliki ketertarikan yang kecil kepada berita yang ada. Kebiasan mahasiswa yang aktif pada saat mendengarkan berita yang disiarkan di televisi adalah menggunakan gadget mereka untuk melakukan hal lain. Hal yang dilakukan adalah seperti mencari informasi lengkap terkait suatu berita atau bahkan didiskusikan/dibicarakan dengan orang lain. Kebanyakan dari mereka yang melihat berita tersebut adalah menyebarkan berita itu lagi melalui media sosial mereka.

Berdasarkan data tabel 2, mahasiswa mengakses atau menemukan berita menggunakan media dengan banyak pengguna yaitu media sosial (80\%), Youtube (54\%), TV (17\%), Diskusi dengan Teman (26\%), Percakapan dengan Dosen (4\%), dan Berita Daring (2\%). Media yang paling banyak digunakan mahasiswa adalah media sosial, seperti Instagram, Line, Whatsapp, dsb. Hasil ini sesuai dengan data pengguna internet dari APJII dan penelitian sebelumnya oleh Andi Saputra. Berdasarkan penelitian sebelumnya, pengguna internet dan media sosial terbanyak berada pada rentang usia 19 tahun ke atas atau mahasiswa. Dengan penelitian yang menunjukkan bahwa mahasiswa lebih sering mengakses media sosial Whatsapp dan Instagram disusul dengan Youtube. Kebiasaan mahasiswa dalam mengakses media sosial ini dapat digunakan sebagai ide tempat atau sarana penyebaran berita-berita Indonesia. Oleh karena itu, untuk meningkatkan persepsi mahasiswa terhadap berita-berita Indonesia, berita-berita tersebut harus disebarkan melalui media sosial seperti Instagram dan Line, karena Whatsapp tidak mendukung penyebaran berita, dan penyebaran melalui media Youtube.

Berdasarkan dari hasil data yang didapat melalui survei yang disebarkan, mahasiswa/i memiliki tingkat Persepsi terhadap keadaan politik di Indonesia adalah cukup mengerti dan mengetahuinya. Walaupun begitu banyak juga yang masih tidak mengetahui atau jarang, hal ini disebabkan karena kebanyakan mahasiswa/i sibuk dengan kegiatan perkuliahan lainnya dan tugastugas yang diberikan. Selain itu juga, mereka banyak pula mendengarkan atau membaca berita dari sosial media dan Youtube. Hal ini disebabkan karena kedua hal tersebut sangat mudah diakses dan bisa dibawa kemana-mana (handphone 
/gadget). Mereka juga tidak setuju apabila diadakannya lagi amandemen UUD 1945 dan lebih memilih untuk tidak mengubah lagi isi dari UUD 1945. Dengan harapan bahwa perubahan ini tidak merubah sistem pemerintahan atau dasar negara Indonesia dan lebih pada pengoptimisasian alur kerja lembaga pemerintahan di Indonesia.

\section{KESIMPULAN}

Berdasarkan hasil pengamatan di atas, dapat disimpulkan bahwa: Mahasiswa/i sering, mendekati kadang, dengan nilai indeks 2.261, mengikuti berita politik yang terjadi di Indonesia dan juga lebih dari setengah mahasiswa/I mengetahui/pernah mendengar tentang isu wacana amandemen UUD 1945 ke-5. Mahasiswa/i sering mengakses berita melalui platform media sosial (80.4\%), Youtube (54.3\%), dan TV (37\%). Mahasiswa/i tidak setuju dengan dilakukannya amandemen UUD NRI 1945 Kelima. Mahasiswa berharap untuk pengoptimisasian alur kerja lembaga pemerintahan, tanpa merubah sistem pemerintahan di Indonesia.

\section{DAFTAR PUSTAKA}

Adiarsi, Gracia Rachmi et al. (2015). Literasi Media Internet di Kalangan Mahasiswa. Binus Journal Publishing, Vol. 6 No. 4 (2015) Humaniora. https://doi.org/10.21512/humaniora.v6i4.3376.

Anggraini, Yesi, Armen Yasir, and Zulkarnain Ridlwan. 2016. PERBANDINGAN PERENCANAAN PEMBANGUNAN NASIONAL SEBELUM DAN SESUDAH

AMANDEMEN UNDANG-UNDANG DASAR 194. Fiat Justisia: Jurnal Ilmu Hukum 9 (1). https://doi.org/10.25041/fiatjustisia.v9no1.589.

Asosiasi Pengguna Jasa Internet Indonesia/APJII. 2020. "Laporan Survei Internet APJII 2019 2020 [Q2]".

Azka, Fatih et al. (2018). Kecemasan Sosial dan Ketergantungan Media Sosial pada Mahasiswa. PSYMPATHIC: Jurnal Ilmiah Psikologi, Volume 5, Nomor 2, 2018: 201-210. https://doi.org/10.15575/psy.v5i2.3315.

Basuki, U. (2015). Amandemen Kelima Undang-Undang Dasar 1945 sebagai Amanat Reformasi dan Demokrasi. PANGGUNG HUKUM, 1(1).

Basuki, U. Amandemen Kelima: Suatu Kajian Penyempurnaan Amandemen UUD 1945. Dalam Jurnal Sosio-Religia, $8 . \quad \underline{\text { https://www.aifis- }}$ digilib.com/uploads/1/3/4/6/13465004/06 udiyo_basuki.pdf Darusman,

Dewantara, J. A., Hermawan, Y., Yunus, D., Prasetiyo, W. H., Efriani, Arifiyanti, F., \& Nurgiansah, T. H. (2021). Anti-Corruption Education as an Effort to Form Students With Character Humanist and Law-Compliant. Jurnal Civics: Media Kajian Kewarganegaraan, 18(1), 70 81.

Dewantara, J. A., \& Nurgiansah, T. H. (2021a). Building Tolerance Attitudes Of PPKN Students Through Multicultural Education Courses. Jurnal Etika Demokrasi, 6(1), 103-115.

Dewantara, J. A., \& Nurgiansah, T. H. (2021b). Efektivitas Pembelajaran Daring di Masa Covid19 Bagi Mahasiswa Universitas PGRI Yogyakarta. Jurnal Basicedu: Research \& Learning in Elementary Education, 5(1), 367-375.

Dewantara, J. A., Nurgiansah, T. H., \& Rachman, F. (2021). Mengatasi Pelanggaran Hak Asasi Manusia dengan Model Sekolah Ramah HAM (SR-HAM). Edukatif: Jurnal Ilmu Pendidikan, 3(2), 261-269.

Yoyo M. 2013. KAJIAN YURIDIS URGENSI AMANDEMEN KELIMA UNDANG-UNDANG DASAR 1945 DALAM SISTEM HUKUM KETATANEGARAAN INDONESIA. 
https://academicjournal.yarsi.ac.id/index.php/Jurnal-ADIL/article/view/801

Fatwa, Andi Mappetahang. 2009. Potret konstitusi pasca amandemen UUD 1945. Jakarta: Penerbit Buku Kompas.

Ghafur, Jamaludin. (2007). Penguatan Lembaga DPD Melalui Amandemen Ulang Lembaga MPR. JURNAL HUKUM NO. 3 VOL. 14 JULI 2007: 366 - 412. ISSN 0854-8498. https://journal.uii.ac.id/IUSTUM/article/view/1079.

Hanoum, R. Nadia et al. (2014). Mengembangkan Keterampilan Berpikir Tingkat Tinggi Mahasiswa Melalui Media Sosial. Edutech, Tahun 13, Vol.1, No.3, Oktober 2014. https://doi.org/10.17509/edutech.v13i3.3093.

Ilhamsyah. (2015). Televisi Nasional dan Tren Mahasiswa. Medan : Universitas Muhamadiyah Sumatera Utara. https://www.academia.edu/33771988/TELEVISI NASIONAL DAN TREN MAHASI SWA.

Indrayana, D. 2007. Amandemen UUD 1945: Antara mitos dan pembongkaran. Mizan Pustaka.

Lutfi, Chairul, 2018. Penguatan DPD RI Melalui Amandemen Kelima UUD NRI 1945. https://www.academia.edu/42350444/PENGUATAN_DPD_RI_MELALUI_AMANDEMEN_ KELIMA_UUD_NRI_1945

Nurgiansah, T. H. (2021a). Pendidikan Pancasila. In Solok: CV Mitra Cendekia Media.

Nurgiansah, T. H. (2021b). Pendidikan Pancasila Sebagai Upaya Membentuk Karakter Jujur. Jurnal Pendidikan Kewarganegaraan Undiksha, 9(1), 33-41.

Nurgiansah, T. H., Dewantara, J. A., \& Rachman, F. (2020). The Implementation of Character Education in the Civics Education Syllabus at SMA Negeri 1 Sleman. Jurnal Etika Demokrasi, 5(2), 110-121.

Nurgiansah, T. H., \& Pringgowijoyo, Y. (2020). Pelatihan Penggunaan Model Pembelajaran Jurisprudensial Pada Guru Di KB TK Surya Marta Yogyakarta. KUAT: Keuangan Umum Dan Akuntansi Terapan. PKNSTAN, 2(1).

Nurgiansah, T. H., \& Widyastuti, T. M. (2020). Membangun Kesadaran Hukum Mahasiswa PPKn UPY Dalam Berlalu Lintas. Civic Edu: Jurnal Pendidikan Kewarganegaraan Universitas Pasundan, 2(2), 97-102. https://doi.org/10.1017/CB09781107415324.004

Nurhalimah, Sitti et al. 2019. Media Sosial Dan Masyarakat Pesisir: Refleksi Pemikiran Mahasiswa Bidikmisi. Yogyakarta : CV Budi Utama.

Saputra, Andi. (2019). Survei Penggunaan Media Sosial di Kalangan Mahasiswa Kota Padang Menggunakan Teori Uses and Gratifications. BACA: JURNAL DOKUMENTASI DAN INFORMASI, [S.l.], v. 40, n. 2, p. 207-216, may 2019. ISSN 2301-8593. Date accessed: 03 may 2021. doi:https://doi.org/10.14203/j.baca.v40i2.476

Sulthan, Muhammad dan S. Bekti Istiyanto. Model Literasi Media Sosial Bagi Mahasiswa. Jurnal ASPIKOM, [S.l.], v. 3, n. 6, p. 1076-1092, mar. 2019. ISSN 2548-8309. Date accessed: 03 may 2021. doi:http://dx.doi.org/10.24329/aspikom.v3i6.280.

Suyanto, Totok et al. (2018). Persepsi mahasiswa terhadap kemunculan berita bohong di media sosial. Jurnal Civics: Media Kajian Kewarganegaraan, [S.l.], v. 15, n. 1, p. 52-61, may 2018. ISSN 2541-1918. Date accessed: 03 may 2021. doi:https://doi.org/10.21831/jc.v15i1.17296.

Syah, T. 2009. Amandemen UUD Negara RI Tahun 1945 Menghasilkan Sistem Checks And Balances Lembaga Negara. https://pkh.komisiyudisial.go.id/files/ Karya\%20TulisTaufiqurrohman\%2001.pdf.

Tutik, Titik Triwulan. 2016. Konstruksi Hukum Tata Negara Indonesia Pasca Amandemen UUD 1945. Jakarta : Prenada Media Group.

Undang-Undang Nomor 5 Tahun 2004 tentang Mahkamah Agung. 
Zuria, Siti Fatimatus dan Totok Suyanto. (2018). Kajian Keterampilan Intelektual Mahasiswa UNESA dalam Mengenali Berita Hoax di Media Sosial. Kajian Moral dan Kewarganegaraan. Volume 06 Nomor 06 Jilid III Tahun 2018, 565 - 580. https://jurnalmahasiswa.unesa.ac.id/index.php/jurnal-pendidikan-kewarganegar aa/article/view/24906 